\title{
BMJ Open Risk of depressive disorders after tobacco smoking cessation: a retrospective cohort study in Fukuoka, Japan
}

Takako Fujita, ${ }^{\oplus 1,2}$ Akira Babazono, ${ }^{1,3}$ Yumi Harano, ${ }^{1}$ Peng Jiang ${ }^{1}$

To cite: Fujita T, Babazono A, Harano Y, et al. Risk of depressive disorders after tobacco smoking cessation: a retrospective cohort study in Fukuoka, Japan. BMJ Open 2019;9:e025124. doi:10.1136/ bmjopen-2018-025124

- Prepublication history for this paper is available online. To view these files please visit the journal online (http://dx.doi. org/10.1136/bmjopen-2018025124).

Received 2 July 2018 Revised 14 February 2019 Accepted 19 February 2019

A) Check for updates

(c) Author(s) (or their employer(s)) 2019. Re-use permitted under CC BY-NC. No commercial re-use. See rights and permissions. Published by BMJ.

${ }^{1}$ Department of Healthcare Administration and

Management, Graduate School of Medical Sciences, Kyushu University, Fukuoka, Japan ${ }^{2}$ Department of Health Sciences, Faculty of Medical Sciences, Kyushu University, Fukuoka, Japan

${ }^{3}$ Department of Healthcare Administration and

Management, Faculty of Medical Sciences, Kyushu University,

Fukuoka, Japan

Correspondence to

Ms Takako Fujita;

tafujita@med.kyushu-u.ac.jp

\section{ABSTRACT}

Objective We sought to examine the effect of smoking cessation on subsequent development of depressive disorders.

Design This was a retrospective cohort study. Methods We used administrative claim and health check data from fiscal years 2010 to 2014, obtained from the largest health insurance association in Fukuoka, Japan. Study participants were between 30 and 69 years old. The end-point outcome was incidence of depressive disorders. Survival analysis and Cox proportional hazards models were conducted. The evaluated potential confounders were sex, age, standard monthly income and psychiatric medical history.

Results The final number of participants was 87255 , with 7841 in the smoking cessation group and 79414 in the smoking group. The result of survival analysis showed no significant difference in depressive disorders between the two groups. The results of Cox proportional hazards models showed no significant difference by multivariate analysis between participants, including users of smoking cessation medication (HR 1.04, 95\% $\mathrm{Cl} 0.89$ to 1.22) and excluding medication use ( $\mathrm{HR} 0.97,95 \% \mathrm{Cl} 0.82$ to 1.15 ). Conclusions The present study showed that there were no significant differences with respect to having depressive disorders between smoking cessation and smoking groups. We also showed that smoking cessation was not related to incidence of depressive disorders among participants, including and excluding users of smoking cessation medication, after adjusting for potential confounders. Although the results have some limitations because of the nature of the study design, our findings will provide helpful information to smokers, health professionals and policy makers for improving smoking cessation.

\section{INTRODUCTION}

Tobacco smoking is a major public health problem and is currently responsible for the deaths of about 6 million people worldwide each year, with many of these deaths occurring prematurely. ${ }^{1}$ The worldwide age-standardised prevalence of daily smoking in 2015 was $25.0 \%$ among men and $5.4 \%$ among women, ${ }^{2}$ and the rate in Japan in 2015 was

\section{Strengths and limitations of this study}

- This was a retrospective cohort study including 87255 participants.

- We followed up participants for approximately 4 years.

- We evaluated smokers who quit with the use of any smoking cessation method, and also examined a group that did not use stop smoking medication.

- We considered monthly income as a confounder, although many previous studies in smoking cessation research have not included this factor.

- This study has some limitations, such as the possible existence of confounding and reverse causality; in addition, the exact date of smoking cessation could not be identified, biochemical measures were not included and participants with mandatory smoking cessation owing to disease were not excluded.

higher: $29.6 \%$ among men and $9.4 \%$ among women. ${ }^{3}$ Some smokers who make serious attempts to stop soon return to smoking. ${ }^{4}$ The WHO Framework Convention on Tobacco Control (WHO FCTC) is the first global public health treaty, adopted in 2003 and entered into force in $2005 .^{5}$ Although Japan took part in the WHO FCTC, the tobacco policies in Japan are among some of the weakest, especially regarding protection from exposure to tobacco smoke. ${ }^{3}$ According to Article 14 of the WHO FCTC, all parties are required to develop and disseminate national guidelines on tobacco cessation, ${ }^{5}$ but such guidelines have only been partially implemented in Japan. ${ }^{3}$

Smokers attempt smoking cessation either without assistance or with the use aids, such as prescribed medication (varenicline, bupropion), nicotine replacement medications (nicotine gum, patch, inhaler), support from a doctor or other health professional or special stop-smoking services (clinics, specialists) or telephone and online quitline services. ${ }^{6}$ There has been a concern that 
smoking cessation might be associated with psychiatric disorders $^{7}$ such as anxiety or depression, among other withdrawal symptoms owing to nicotine addiction. ${ }^{48}$ Most withdrawal symptoms reach maximum intensity in the first 24-48 hours and then gradually diminish over a period of a few weeks. ${ }^{8}$ Some symptoms, such as depressive symptoms, often do not resolve within 45 days. ${ }^{9}$ However, some studies have reported that smoking cessation is associated with reduced depression, anxiety, and stress and improved positive mood and quality of life, as compared with continuing to smoke, even in depressed smokers. ${ }^{10-12}$ These relationships are difficult to validate because of confounding and reverse causality. ${ }^{13}$ Withdrawal and craving might be potential predictors of relapse, and might mediate or cause treatment effects. ${ }^{14}$ The proportion of the global population with depression in 2015 was estimated to be $4.4 \%^{15}$; therefore, further investigation of the relationship between smoking cessation and depressive disorders are considered to be an urgent matter in promoting smoking cessation. Consequently, more research is needed.

Only varenicline and nicotine patches are permitted to be prescribed under the insurance coverage for smoking cessation in Japan. ${ }^{1617}$ According to the required review by the US Food and Drug Administration of a large clinical trial of varenicline, the risk of mental health side effects was present, especially in patients currently being treated for mental illnesses or those who had been treated for mental illnesses in the past. However, most people who had these side effects did not have serious consequences. As a result, the boxed warning was removed from the varenicline label, ${ }^{7}$ although notes on the possibility of mental health side effects were retained in the warnings and precautions. It has also been reported that there is no significant increase in neuropsychiatric adverse events attributable to varenicline or bupropion, relative to the nicotine patch or placebo. ${ }^{18} 19$ According to the USA, prescribing information for varenicline in December of 2016, depression, rarely including suicidal ideation, has also been reported in smokers undergoing a smoking cessation attempt without medication. ${ }^{720}$ Previous studies have investigated whether psychiatric symptoms worsen after smoking cessation among people with medical histories of these symptoms. ${ }^{18} 1921$ However, most studies assessed smokers who were using smoking cessation medication; there are few studies among people who attempt any method of smoking cessation, such as using prescribed medication, using nicotine replacement medications, or using no smoking cessation methods, especially in Asian countries. In addition, although some studies have reported that the rates of depression ${ }^{22}$ and tobacco use are high among lower socioeconomic groups, ${ }^{23}$ these studies did not evaluate whether income status was related to the incidence of depression following smoking cessation.

Even though a number of studies investigating the relationship between smoking cessation and depressive disorders have been conducted, these studies have not considered income level and any method of smoking cessation, including or excluding medication, especially in Asian countries and over the long term. Thus, we used administrative claim and health check data of health insurance beneficiaries in Japan, to assess whether smoking cessation was related to depressive disorders.

\section{METHODS}

\section{Study population and design}

The Japan Health Insurance Association is the largest employee's health insurance association in Japan. This association covers healthcare for employees of medium-sized or smaller companies and their families, totaling about 37165000 people, which is equivalent to $29.3 \%$ of the population of Japan in March 2015. ${ }^{24}$ The association maintains administrative claim, health check and long-term care insurance data of its beneficiaries. Administrative claim data include medical, pharmacy and dental data; we used medical and pharmacy data in this study. Questionnaires are administered during health checks and the responses are also included in the health check data. The smoking section of the questionnaire includes the yes/no question 'Do you smoke habitually? (Smoking a total of more than 100 cigarettes after the first time of smoking or smoking for more than 6 months, and smoking in the previous 1 month).' This definition is used in some other countries. ${ }^{2526}$

The Fukuoka branch of the Japan Health Insurance Association had 1809115 beneficiaries as of March $2015^{27}$ and we used the data of employees. We included participants who were aged 30-69 years on 1 April 2011. Although most employees undergo health checks at their workplace, people under 30 years old participate in these health checks far less often than employees in other age groups; in addition, working people aged over 70 years undergo health checks the least often among all age groups. Thus, this study included participants aged 30-69 years. Employees who underwent health checks in fiscal years 2010 and 2011, and those who reported smoking within the previous 1 month on the questionnaire in fiscal year 2010, were considered potential study participants. The study finally included 87255 participants, comprising a smoking cessation group with 7841 participants and a smoking group with 79414 , who had both administrative claim data and health check data. The smoking cessation group consisted of those who answered 'No' to smoking within the previous 1 month in fiscal year 2011; the smoking group comprised participants who answered 'Yes' to that question. Figure 1 shows the flow diagram to select participants.

Administrative claim and health check data were de-identified by constructing specific databases using a work station with no connection to any networks.

\section{Patient and public involvement}

We used administrative claim data and health check data and did not involve patients in this study. 


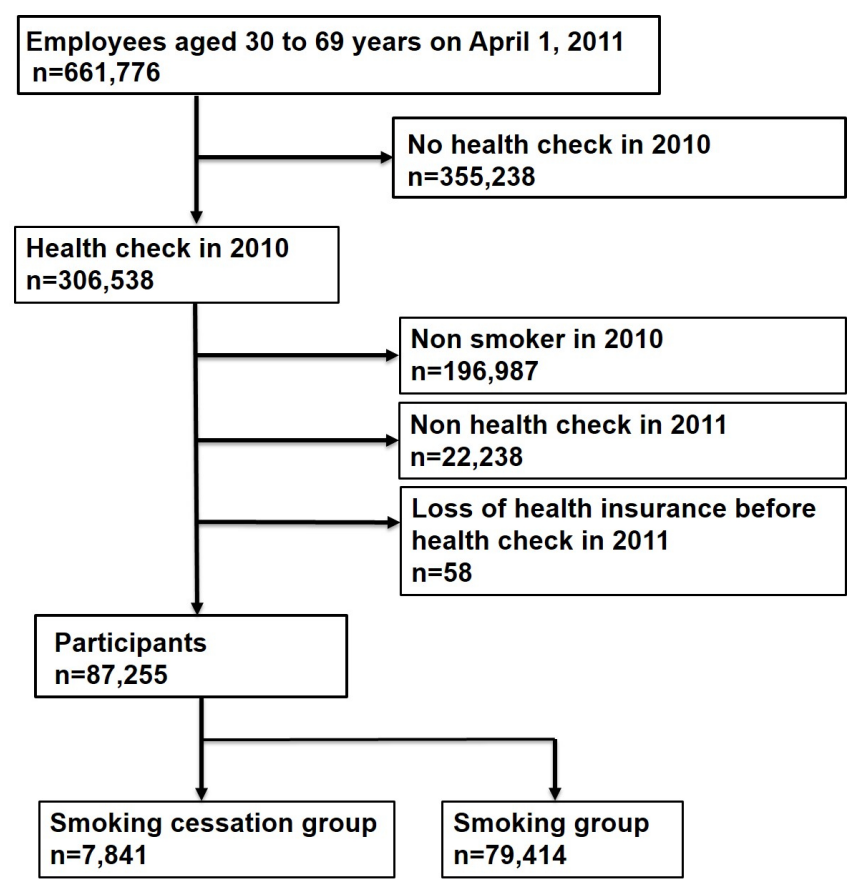

Figure 1 Flow diagram of inclusion/exclusion criteria.

\section{Outcome}

The end-point outcome was incidence of depressive disorders between health checks in 2011 and the end of fiscal year 2014 (ie, 31 March 2015). In this study, depressive disorder was defined as receiving any medical care for depressive episodes, classified as ICD-10 code F32 in the medical administrative claim data.

Participants who attempted to stop smoking without the use of smoking cessation medication were also included in the analysis. Participants who used smoking cessation medication were defined as those who were prescribed varenicline or nicotine patches after the 2010 health check, as approved in Japanese health insurance fee schedules.

\section{Statistical analysis}

SQL server 2014 was used to extract the data and Stata V.14.2 was used for all analyses. First, survival analysis was performed using the Kaplan-Meyer method and log-rank test, to compare episodes of depressive disorders between the smoking cessation and smoking groups. The starting point was defined as the day of undergoing the health check in fiscal year 2011, and the end point was defined as the day of diagnosis of a depressive disorder.

Participants without the outcome event were censored at the time any of the following occurred: loss of health insurance, no health check received (by the end of the fiscal year), resumption of smoking if in the smoking cessation group (the identified time of smoking) and smoking cessation if in the smoking group (the identified time of smoking cessation).

Next, univariate and multivariate Cox proportional hazards models were used to examine associations between exposures and outcomes, to yield HRs and 95\%
CIs. The evaluated potential confounders were sex, age, standard monthly income and psychiatric medical history. The age category was divided into 10 year intervals. Standard monthly income was divided into three groups: less than US\$2500, US\$2500-3499 and US\$3500 and above, because the average income was approximately equivalent to US\$3050 in 2011 in Japan (US $\$ 1=\mathrm{J} 100$ yen). ${ }^{28}$ Psychiatric medical history was defined having received healthcare services before the 2011 health check for the following diseases: ICD-10 F20-29 (schizophrenia, schizotypal, delusional and other non-mood psychotic disorders), F30-39 (mood disorders) and F40-48 (anxiety, dissociative, stress-related, somatoform and other non-psychotic mental disorders). No missing data were found for each variable.

Data of participants who did not use stop-smoking medication (varenicline or nicotine patches) were analysed in a similar manner.

\section{RESULTS}

Demographic information of the present study participants is shown in table 1. The proportion of participants with a history of healthcare received for depressive disorders was $2.3 \% \quad(n=1989)$, with $2.2 \% \quad(n=173)$ in the smoking cessation group and 2.3\% $(\mathrm{n}=1816)$ in the smoking group. The proportion of participants with a psychiatric medical history was $5.2 \% \quad(n=4559)$, with $6.3 \%(\mathrm{n}=491)$ in the smoking cessation group and $5.1 \%$ $(\mathrm{n}=4068)$ in the smoking group.

Figure 2 shows the results of comparing the time to outcome using Kaplan-Meier survival estimates. The results showed that there was no significant difference between the smoking cessation group and smoking group with respect to the incidence of depressive disorders. A log-rank test was also conducted, with $\chi^{2}=1.56$ and $p=0.21$.

Table 2 shows the results of univariate and multivariate Cox proportional hazards models. The results revealed that the variables sex, age, standard monthly income and psychiatric medical history had significant associations with depressive disorders, whereas smoking cessation was not significant, with HR $1.10(95 \% \mathrm{Cl} 0.94$ to 1.29$)$ by univariate analysis and HR 1.04 (95\% $\mathrm{Cl} 0.89$ to 1.22$)$ by multivariate analysis.

Data of participants who did not use stop-smoking medication (varenicline or nicotine patches) were analysed in a similar manner. A total 86092 participants did not use medication, including 7248 in the smoking cessation group and 78844 in the smoking group. The proportion of participants with a history of receiving care for depressive disorders was $2.3 \% \quad(n=1946)$, with $2.0 \% \quad(n=148)$ in the smoking cessation group and $2.3 \%(\mathrm{n}=1798)$ in the smoking group; the proportion with a psychiatric medical history was $5.2 \% \quad(\mathrm{n}=4444)$, with $6.0 \% \quad(\mathrm{n}=437)$ in the smoking cessation group and $5.1 \%(\mathrm{n}=4007)$ in the smoking group.

The results of comparing time to outcome using Kaplan-Meier survival estimates showed that there was no 
Table 1 Number and proportion of participants (including users of smoking cessation medication) for fiscal years 2010-2014 in Fukuoka, Japan

\begin{tabular}{|c|c|c|c|c|}
\hline Variable & $\begin{array}{l}\text { Smoking } \\
\text { cessation group }\end{array}$ & Smoking group & Total & $P$ value \\
\hline Total & $\mathrm{n}=7841$ & $\mathrm{n}=79414$ & $\mathrm{n}=87255$ & \\
\hline Sex & & & & $<0.001$ \\
\hline Male & $6274(80.0 \%)$ & $65840(82.9 \%)$ & $72114(82.6 \%)$ & \\
\hline Female & $1567(20.0 \%)$ & $13574(17.1 \%)$ & $15141(17.4 \%)$ & \\
\hline Age category & & & & $<0.001$ \\
\hline $30-39$ & $1680(21.4 \%)$ & $16974(21.4 \%)$ & $18654(21.4 \%)$ & \\
\hline $40-49$ & $2676(34.1 \%)$ & $28576(36.0 \%)$ & $31252(35.8 \%)$ & \\
\hline $50-59$ & $2418(30.8 \%)$ & $24477(30.8 \%)$ & $26895(30.8 \%)$ & \\
\hline $60-69$ & $1067(13.6 \%)$ & $9387(11.8 \%)$ & $10454(12.0 \%)$ & \\
\hline \multicolumn{4}{|c|}{ Standard monthly remuneration category* } & 0.003 \\
\hline Under US $\$ 2500$ & $2495(31.8 \%)$ & $24887(31.3 \%)$ & $27382(31.4 \%)$ & \\
\hline US\$2500-3499 & 2469 (31.5\%) & 26457 (33.3\%) & $28926(33.2 \%)$ & \\
\hline US $\$ 3500$ and more & 2877 (36.7\%) & $28070(35.3 \%)$ & 30947 (35.5\%) & \\
\hline \multicolumn{4}{|l|}{ Psychiatric medical histories } & $<0.001$ \\
\hline Yes & $491(6.3 \%)$ & $4068(5.1 \%)$ & $4559(5.2 \%)$ & \\
\hline No & $7350(93.7 \%)$ & $75346(94.9 \%)$ & $82696(94.8 \%)$ & \\
\hline Stop-smoking medication & $593(7.6 \%)$ & $570(0.7 \%)$ & $1163(1.3 \%)$ & $<0.001$ \\
\hline Varenicline & $579(7.4 \%)$ & $536(0.7 \%)$ & $1115(1.3 \%)$ & \\
\hline Nicotine patches & $15(0.2 \%)$ & $36(0.0 \%)$ & $51(0.1 \%)$ & \\
\hline No quit-smoking medication & $7248(92.4 \%)$ & $78844(99.3 \%)$ & $86092(98.7 \%)$ & \\
\hline \multicolumn{4}{|l|}{ Depressive disorders } & 0.649 \\
\hline Yes & $173(2.2 \%)$ & $1816(2.3 \%)$ & $1989(2.3 \%)$ & \\
\hline No & 7668 (97.8\%) & 77598 (97.7\%) & 85266 (97.7\%) & \\
\hline
\end{tabular}

*US $\$ 1=100$ yen.

significant difference between the smoking cessation and smoking groups with respect to the incidence of depressive disorders. A log-rank test was also conducted, with $\chi^{2}=0.07$ and $\mathrm{p}=0.79$.

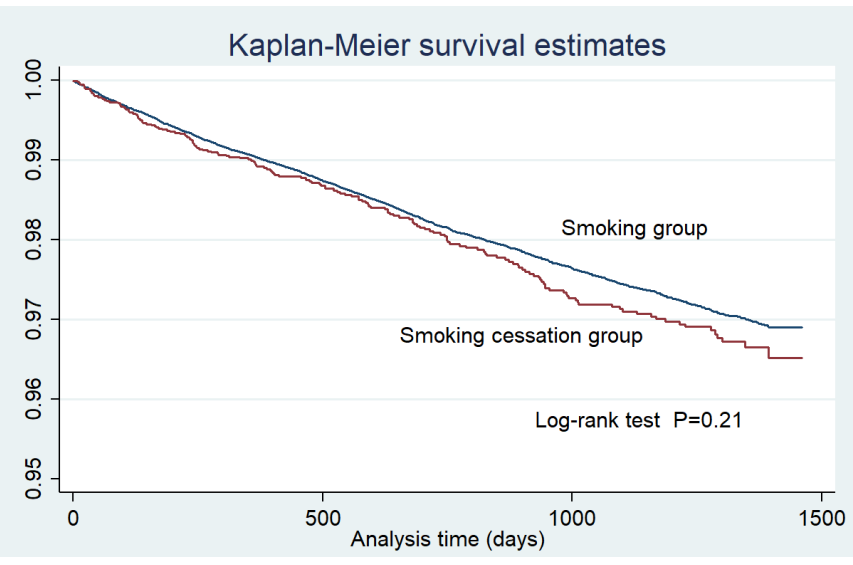

Figure 2 Kaplan-Meier survival estimates for days until diagnosis of a depressive disorder (including users of smoking cessation medication) for fiscal years 2010-2014 in Fukuoka, Japan.
Table 3 shows the results of univariate and multivariate Cox proportional hazards regression models. There were significant differences among the variables of sex, age, standard monthly income and psychiatric medical history with respect to the incidence of depressive disorders. Smoking cessation was not significant, with HR $1.02(95 \%$ $\mathrm{Cl} 0.86$ to 1.21$)$ by univariate analysis and HR $0.97(95 \%$ Cl 0.82 to 1.15 ) by multivariate analysis.

\section{DISCUSSION}

We found no significant differences between the smoking cessation group and the smoking group for depressive disorders in long-term follow-up, after adjusting for sex, age, standard monthly income and psychiatric medical history. We similarly examined the data of participants, excluding users of stop-smoking medication and there was also no significant difference.

Our analysis also showed that sex, age, standard monthly income and psychiatric medical history were significantly associated with depressive disorders following smoking cessation. The WHO has reported that globally, 
Table 2 Effect of smoking cessation on depressive disorders in Cox proportional hazards models (including users of smoking cessation medication) for fiscal years 2010-2014 in Fukuoka, Japan

\begin{tabular}{|c|c|c|c|c|c|c|}
\hline \multirow[b]{2}{*}{ Variables } & \multicolumn{3}{|c|}{ Univariate } & \multicolumn{3}{|c|}{ Multivariate } \\
\hline & HR & $95 \% \mathrm{Cl}$ & $P$ value & HR & $95 \% \mathrm{Cl}$ & $P$ value \\
\hline Male & 0.67 & 0.61 to 0.75 & 0.000 & 0.86 & 0.76 to 0.96 & 0.009 \\
\hline Age & 0.87 & 0.83 to 0.92 & 0.000 & 0.85 & 0.81 to 0.89 & 0.000 \\
\hline Standard monthly income & 0.88 & 0.84 to 0.93 & 0.000 & 0.92 & 0.87 to 0.98 & 0.006 \\
\hline $\begin{array}{l}\text { Psychiatric medical } \\
\text { histories }\end{array}$ & 9.22 & 8.38 to 10.14 & 0.000 & 9.03 & 8.20 to 9.94 & 0.000 \\
\hline Smoking cessation & 1.10 & 0.94 to 1.29 & 0.212 & 1.04 & 0.89 to 1.22 & 0.595 \\
\hline
\end{tabular}

depression is about two times as common in women as in men. ${ }^{29}{ }^{30}$ Another study also reported that the rate of depression in lower socioeconomic groups is high ${ }^{22}$; our results for sex and standard monthly income were consistent with those findings. The prevalence of depression increases with age, up to $55-74$ years, ${ }^{15}$ but our study showed that younger age was significantly associated with depressive disorders. Being unemployed increases the risk for developing mental illness, with strong evidence for the development of depression. ${ }^{31}$ However, our study participants were all employed, so this did not affect our study.

People who have the intention to stop smoking and who work as health professionals or health-related service providers might have concerns about depressive disorders after smoking cessation. The present results could provide helpful information that could not influence whether prescribed stop-smoking medication is used or not because smoking cessation is not associated with depressive disorders in the long term. Moreover, successful smoking cessation has great benefits for reducing the risk of many diseases, such as lung cancer, chronic obstructive pulmonary disease, cardiovascular disease and other disorders. ${ }^{32}$ However, most withdrawal symptoms reach maximum intensity within a few days ${ }^{8}$ and some symptoms can persist for more than 45 days. ${ }^{9}$ Consequently, health professionals would be required to help people who attempt smoking cessation not to relapse because of withdrawals, especially in the first few months after quitting. In addition, our results could provide evidence that can be used to promote smoking cessation programmes as part of government policies.
The present study has several limitations. First, because of the nature of retrospective cohort studies, biases could exist, even though we adjusted for potential confounding variables. For example, previous studies have suggested that the link between depressive symptoms and relapse is significantly mediated by craving. ${ }^{33}$ We could not assess this, and smokers in our sample might have included those relapsed because of craving. Second, the exact date of smoking cessation could not be identified because it was not recorded among the health check and administrative claim data. Many smokers make repeated attempts to stop smoking following unsuccessful experiences, both with and without the use of Over-the-Counter medicines. In addition, varenicline can be taken before stopping smoking. Therefore, the date of the health check on which participants reported not smoking was used as the surrogate. Third, in the present study, we did not carry out any biochemical measures to verify smoking cessation, such as measurement of serum cotinine concentrations and expiratory carbon monoxide levels. We identified smoking status using the questionnaires administered during health checks as well as administrative claim data, and these biochemical measures are not recorded in these records. Finally, we did not exclude participants with mandatory smoking cessation owing to development of cancer, cardiovascular disease, cerebrovascular disease, and other related diseases. It has been reported that patients with serious diseases could be more susceptible to depressive disorders. ${ }^{34}$ Studies have reported a prevalence rate of $47 \%$ for psychiatric disorders in a cohort of cancer patients, ${ }^{35}$ at least one in five for clinically significant depression in patients with heart failure, ${ }^{36}$ and a

Table 3 Effect of smoking cessation on depressive disorders by Cox proportional hazards models (excluding users of smoking cessation medication) for fiscal years 2010-2014 in Fukuoka, Japan

\begin{tabular}{|c|c|c|c|c|c|c|}
\hline \multirow[b]{2}{*}{ Variables } & \multicolumn{3}{|c|}{ Univariate } & \multicolumn{3}{|c|}{ Multivariate } \\
\hline & HR & $95 \% \mathrm{Cl}$ & $P$ value & HR & $95 \% \mathrm{Cl}$ & $P$ value \\
\hline Male & 0.68 & 0.61 to 0.76 & 0.000 & 0.87 & 0.77 to 0.98 & 0.020 \\
\hline Standard monthly income & 0.88 & 0.83 to 0.93 & 0.000 & 0.91 & 0.86 to 0.97 & 0.003 \\
\hline Psychiatric medical histories & 9.32 & 8.46 to 10.27 & 0.000 & 9.15 & 8.30 to 10.08 & 0.000 \\
\hline
\end{tabular}


cumulative depression incidence of up to $52 \%$ within 5 years of a stroke event. ${ }^{37}$ If we had excluded participants who were forced to stop smoking for such health-related reasons in this study, the risk of depressive disorders after smoking cessation might have been lower.

Acknowledgements We thank the Fukuoka Branch of the Japan Health Insurance Association for providing health claim data. We also thank Analisa Avila, ELS, of Edanz Group (www.edanzediting.com/ac) for editing a draft of this manuscript.

Contributors TF lead the study design, conducted the literature search, extracted and analyzed the data, and wrote the manuscript. AB contributed to the study design, analysis and manuscript revision. YH and PJ contributed to the study design and analysis.

Funding The authors have not declared a specific grant for this research from any funding agency in the public, commercial or not-for-profit sectors.

Competing interests None declared.

Patient consent for publication Not required.

Ethics approval This study was approved by the Institutional Review Board of Kyushu University (Clinical Bioethics Committee of the Graduate School of Healthcare Sciences, Kyushu University).

Provenance and peer review Not commissioned; externally peer reviewed.

Data sharing statement № additional data are available.

Open access This is an open access article distributed in accordance with the Creative Commons Attribution Non Commercial (CC BY-NC 4.0) license, which permits others to distribute, remix, adapt, build upon this work non-commercially, and license their derivative works on different terms, provided the original work is properly cited, appropriate credit is given, any changes made indicated, and the use is non-commercial. See: http://creativecommons.org/licenses/by-nc/4.0/.

\section{REFERENCES}

1. World Health Organization. WHO Global Report on Trends in Prevalence of Tobacco Smoking 2015. World Health OrganizationGeneva; 2015.

2. Reitsma MB, Fullman N, Ng M, et al. GBD 2015 Tobacco Collaborators. Smoking prevalence and attributable disease burden in 195 countries and territories, 1990-2015: a systematic analysis from the Global Burden of Disease Study 2015. Lancet 2017;389:1885-906.

3. World Health Organization. WHO report on the global tobacco epidemic, 2017 Country profile. 2017 https://www.who.int/tobacco/ surveillance/policy/country_profile/en/ (Accessed February 10, 2019).

4. Berrettini W. Nicotine addiction. Am J Psychiatry 2008;165:1089-92.

5. World Health Organization. The WHO Framework Convention on Tobacco Control, 2015.

6. Filippidis FT, Gerovasili V, Vardavas Cl, et al. Determinants of use of smoking cessation aids in 27 European countries. Prev Med 2014;65:99-102.

7. U.S. Food and Drug Administration. FDA revises description of mental health side effects of the stop- smoking medicines Chantix (varenicline) and Zyban (bupropion) to reflect clinical trial findings. 2016.

8. World Health Organization. Addiction to Nicotine. Gender, Women, and The Tobacco Epidemic, 2010:137-50.

9. Gilbert DG, Zuo Y, Rabinovich NE, et al. Neurotransmission-related genetic polymorphisms, negative affectivity traits, and gender predict tobacco abstinence symptoms across 44 days with and without nicotine patch. J Abnorm Psychol 2009;118:322-34.

10. Taylor G, McNeill A, Girling A, et al. Change in mental health after smoking cessation: systematic review and meta-analysis. BMJ 2014;348(February):g1151-22.

11. Morozova M, Rabin RA, George TP. Co-morbid tobacco use disorder and depression: A re-evaluation of smoking cessation therapy in depressed smokers. Am J Addict 2015;24:687-94.

12. Secades-Villa R, González-Roz A, García-Pérez Á, et al. Psychological, pharmacological, and combined smoking cessation interventions for smokers with current depression: A systematic review and meta-analysis. PLoS One 2017;12:e0188849.
13. Sanderson SC, Taylor A, Munafò M. Article does not prove that smoking cessation has an "effect" on mental health. BMJ 2014;348(March):g2018.

14. Shiffman S, West R, Gilbert D; SRNT Work Group on the Assessment of Craving and Withdrawal in Clinical Trials. Recommendation for the assessment of tobacco craving and withdrawal in smoking cessation trials. Nicotine Tob Res 2004;6:599-614.

15. World Health Organization. Depression and Other Common Mental Disorders: Global Health Estimates. Geneva: World Health Organization, 2017.

16. The Japanese Circulation Society, The Japan Lung Cancer Society, Japanese Cancer Association, The Japanese Respiratory Society. Kinen Chiryo No Tame No Hyoujun Tejunsho Dai6han (Standard Protocol for Smoking Cessation Treatment Vol.6), 2014.

17. Division of Cancer Control and Health Promotion Health Services Bureau Ministry of Health Labour and Welfare. Kinen Shien Manual Dai2han(Stop Smoking Support Manual 2nd), 2015.

18. Anthenelli RM, Benowitz NL, West R, et al. Neuropsychiatric safety and efficacy of varenicline, bupropion, and nicotine patch in smokers with and without psychiatric disorders (EAGLES): a double-blind, randomised, placebo-controlled clinical trial. Lancet 2016;387:2507-20.

19. Thomas $\mathrm{KH}$, Martin RM, Davies NM, et al. Smoking cessation treatment and risk of depression, suicide, and self harm in the Clinical Practice Research Datalink: prospective cohort study. BMJ 2013;347(oct11 1):f5704.

20. Pfizer Inc. Chantix (Varenicline) [Prescribing Information]. 2016.

21. Glassman AH, Covey LS, Stetner F, et al. Smoking cessation and the course of major depression: a follow-up study. Lancet 2001;357:1929-32.

22. Patel V, Lund C, Hatherill S, et al. Mental disorders: equity and social determinants. In: Equity, Social Determinats and Public Health Programmes. Geneva: World Health Organization, 2010:115-34.

23. David A, Esson K, Perucic A-M, et al; Tobacco use: equity and social determinants. In: Equity, Social Determinats and Public Health Programmes. Geneva: World Health Organization, 2010:199-217.

24. Japan Health Insurance Association. Jigyou Nenpou Heisei27nendo(Annual Report 2015 Fiscal Year), 2017

25. National Health Interview Survey. CDC/National Center for Health Statistics. https://www.cdc.gov/nchs/nhis/tobacco/tobacco_ glossary.htm (Accessed February 10, 2019).

26. Definitions of smoking status. Ministry of Health, New Zealand Government. https://www.health.govt.nz/our-work/preventativehealth-wellness/tobacco-control/tobacco-control-informationpractitioners/definitions-smoking-status (Accessed February 10, 2019).

27. Japan Health Insurance Association. Kyokai Kenpo Geppou Heisei27nen 3gatsu Toukeihyo(Japan Health Insurance Association Monthly Report March 2015 Statistical Table). 2015.

28. National Statistics Center. e-Stat Kouseinenkin hoken Gyotaibetsu/ Kibobetsu tekiyoujokyoshirabe(Survey on the Employees' Pention Insurance by types of operation and scale). https://www.e-stat.go. jp/stat-search/files?page $=1$ \&layout=datalist $\&$ toukei $=00450464 \&$ tstat $=000001064003 \&$ cycle $=0 \&$ tclass $1=000001069717 \&$ cycle_facet $=$ cycle\&second=1\&second2=1 (Accessed February 10, 2019).

29. World Health Organization. Gender disparities in mental health. 2001;48.

30. Albert PR. Why is depression more prevalent in women? J Psychiatry Neurosci 2015;40:219-21.

31. Zhang S, Bhavsar V. Unemployment as a Risk Factor for Mental Illness: Combining Social and Psychiatric Literature. Adv App/ Sociol 2013;03:131-6.

32. Britton J. Death, disease, and tobacco. Lancet 2017;389:1861-2.

33. Zuo Y, Rabinovich NE, Gilbert DG. Negative affect subtypes and craving differentially predict long-term cessation success among smokers achieving initial abstinence. Psychopharmacology 2017;234:761-71.

34. Spiegel D, Giese-Davis J. Depression and cancer: mechanisms and disease progression. Biol Psychiatry 2003;54:269-82.

35. Derogatis LR, Morrow GR, Fetting J, et al. The prevalence of psychiatric disorders among cancer patients. JAMA 1983;249:751-7.

36. Rutledge T, Reis VA, Linke SE, et al. Depression in heart failure a meta-analytic review of prevalence, intervention effects, and associations with clinical outcomes. J Am Coll Cardiol 2006;48:1527-37.

37. Ayerbe L, Ayis S, Wolfe CD, et al. Natural history, predictors and outcomes of depression after stroke: systematic review and metaanalysis. Br J Psychiatry 2013;202:14-21. 